\title{
THE ALGEBRAICAL DEVELOPMENT OF THE ELLIPTIC PERTURBATIVE FUNCTION USED IN THE THEORIES OF PLANETARY MOTION.
}

\author{
By R. T. A. Innes, F.R.S.S.Af.
}

(Read October 18, 1911.)

The methods of computing the motions of the planets devised by Lagrange and Laplace and used by the great planetary investigators of last century such as Le Verrier, Hansen, and Newcomb, require an expansion of the reciprocal of the distance between two planets. The most general expansion is an algebraical one, which, if it is to be useful in practical work, requires that the eccentricities and mutual inclinations of adjacent planetary orbits should be small-these conditions are fulfilled for all the major planets and for the majority of the minor planets of the solar system. Hence, great attention has been devoted in the past to this algebraical expansion. The most useful, but at the same time the most complicated development, is in terms of the mean anomalies of the planets concerned, and it is this development which is dealt with here. References may be made to the following works :-

Le Verrier, Les Annales de l'Obs. de Paris, vols. i. and x.

Tisserand, Mécanique Celeste, vols. i. and iv.

Hill, Collected Works, vol. ii

Newcomb, American Journal of Mathematics, vol. iii., and Astronomical Papers of the American Ephemeris, vol. v.

Cowell, Monthly Notices of the Royal Astronomical Society, vol. lxix.

The object of the present paper is purely practical ; it is to put in the hands of the computer a development which extends to any order for primary or secondary terms, and is substantially ready for use. A 
numerical application to the theory of the planets Jupiter and Saturn has been commenced, but its completion is still far off.

The most extended tables of the algebraical development of the perturbative function in terms of the mean anomalies, are due to Le Verrier (Les Annales, i. and x.), but a more methodical and general development has been given by Newcomb (Astronomical Papers of the American Ephemeris, v.).

Le Verrier's development has been extended by Boquet to terms of the 8th order of both the eccentricities and mutual inclination, and this limit has also been adopted by Newcomb. The remarks which follow will apply more especially to Newcomb's development, but with suitable changes they can, if necessary, be adapted to Le Verrier's; it is not, however, likely that any one who is familiar with both developments will prefer Le Verrier's-the use of the operator $\mathrm{D}=\boldsymbol{a} \frac{d}{d \boldsymbol{a}}$ by Newcomb is alone sufficient to turn the scale.

Every term of the development has the form*-

$$
e^{n} e_{\mathrm{r}}^{n^{\prime}} \stackrel{k}{\mathrm{P}}_{j \cdot j^{\prime}}^{n} \cos \left(\stackrel{k}{\mathrm{~V}}_{i}+j g+j^{\prime} g^{\prime}\right)
$$

in which $k$ indicates the presence of the factor $\sigma^{2 k}(\sigma=$ sine of semiinclination). The order of this term will be equal to $n+n^{\prime}+2 k$.

This paper will deal with the properties of the quantities $\stackrel{\mathrm{P}}{\mathrm{P}}_{i . j^{\prime}}^{n}$, the expressions for which form the only difficulty in the development. As it is very easy to pass from $\stackrel{\circ}{\mathrm{P}}$ (henceforth written $\mathrm{P}$ ) to $\stackrel{\mathrm{T}}{\mathrm{P}}, \stackrel{2}{\mathrm{P}}, \stackrel{3}{\mathrm{P}}$, \&c., attention will be confined to the former.

In any given term we find a series of this form-

$$
e^{i} e_{\mathrm{I}}^{j^{\prime}}\left(\mathrm{P}_{j . j^{\prime}}^{j j . j^{\prime}}+e^{2} \mathrm{P}_{j}^{j+2 . j^{\prime} j^{\prime}}+e_{\mathrm{I}}^{2} \mathrm{P}_{j . j^{\prime}}^{j . j^{\prime}+2}+e^{2} e_{\mathrm{I}}^{2} \mathrm{P}_{j .}^{i+2 . j_{j^{\prime}}^{\prime}+2}+\& \mathrm{c} .\right)
$$

(In which the suffices only may be negative and then only under certain conditions.)

The first quantity $\mathrm{P}_{j . j^{\prime}}^{j, j^{\prime}}$ will be called the primary term, those multiplied by $e^{2}$ or $e_{1}^{2}$, the secondary terms, those by $e^{2} e_{1}^{2}, e^{4}$ or $e_{1}^{4}$ tertiary terms and so on. Terms in which the suffices $j$ or $j^{\prime}$ are negative are secondary or higher order terms, although they are closely related to the primary terms.

* It is assumed that the reader is conversant with the notation used by Newcomb in the papers above referred to. 
But before going on, a further important simplification can be introduced. With Newcomb, we write-

$$
\begin{gathered}
\mathrm{P}_{j, j^{\prime}}^{n, n n^{\prime}}=\Pi_{j, j^{\prime}}^{n, n^{\prime}} a_{\mathrm{I}} \mathrm{A}_{i}, \\
\text { (Ast. Papers, v., p. 27, \&c.) }
\end{gathered}
$$

in which the operator-

$$
\Pi_{j . j^{\prime}}^{n . n^{\prime}}=\Pi_{j .0}^{n .0} \times \Pi_{0 . j^{\prime}}^{0 . n^{\prime}}
$$

Further, as also discovered by Newcomb, the operator $\Pi_{0 . j^{\prime}}^{o, n^{\prime}}$ can be found from $\Pi_{j .}^{n}$. very simply. Hence the real crux is to find expressions for $\Pi_{j}^{n}$. The primary operator in any term will be $\Pi_{n}^{n}$, the secondary $\Pi_{n}^{n+2}$, the tertiary $\Pi_{n}^{n+4}, \& c ., \& c$. The expresssions to $\Pi_{j}^{8}$ in terms of $i$ and $\mathrm{D}$ are given by Newcomb. The operators with negative suffices are, as already mentioned, at least secondary.

On account of its complexity, it is almost impossible to give a general and useful formula for $\Pi_{j}^{n}$ in terms of the D operators. Such a formula starts thus-

In which-

$$
\begin{aligned}
(-1)^{j} f(n . j) \Pi^{n}= & +\left(2 j i-\frac{n(n-3)}{2}+j^{2}\right. \\
& +\left\{\mathrm{D}^{n}\right. \\
& +\left\{-2 i^{2}\left(n-j^{2}\right)\right. \\
& -j i\left(7-13 n+2 n^{2}+4 j^{2}\right) \\
& +\frac{n}{24}\left(3 n 3-22 n^{2}+45 n-26\right) \\
& +j^{2}\left(n^{2}-6 n+4\right) \\
& \& \mathrm{c} ., \& \mathrm{c} .
\end{aligned}
$$

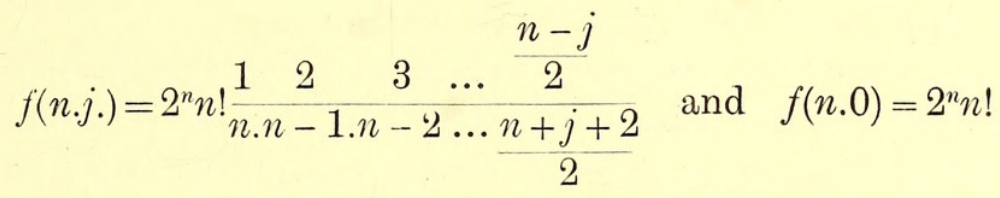

The extent given will merely serve to $n=2$, although it will always serve as a check on the coefficients of the three highest $\mathrm{D}$ operators in any value of $\Pi_{j}^{n}$.

The primary terms are the more important as the succeeding terms are factored by powers of $e^{2}$, \&c. In the "Variation of Elements" method of computing perturbations, the secondary terms become the leading terms in several of the coefficients, but in the final expressions for the perturbationse of the longitude or mean anomaly the primary terms reassert their predominance. Thus in the theory of the motion of the earth we find the following perturbations of the longitude:- 


\begin{tabular}{|c|c|c|c|c|}
\hline Argument. & Action of- & Primary. & Secondary. & Tertiary. \\
\hline$l^{\prime}-\lambda$ & Mercury & $\begin{array}{l} \\
+0.130\end{array}$ & -0.003 & $\mathrm{Nil}$ \\
\hline$l^{\prime}-\lambda$ & Venus & +3.813 & -0.002 & Nil \\
\hline $13 l^{\prime}-8 \lambda$ & Venus & $-1 \cdot 253$ & -0.003 & Nil \\
\hline $13 l^{\prime}-8 \lambda$ & Venus & +2.091 & $-0 \cdot 012$ & Nil \\
\hline$l^{\prime}-\lambda$ & Mars & +0.102 & +0.006 & Nil \\
\hline $15 l^{\prime}-8 \lambda$ & Mars & +0.161 & -0.009 & $\mathrm{Nil}$ \\
\hline $2 l^{\prime}-2 \lambda$ & Jupiter & +1.901 & -0.012 & Nil \\
\hline
\end{tabular}

(See for further examples Le Verrier's "Theory of the Sun" (Les Annales, iv., pp. (9)-(18) ). The secondary terms given appear to be the largest in this theory.)

In the action of Saturn on Jupiter we find-

\begin{tabular}{|c|c|c|c|}
\hline Argument. & Primary. & Secondary. & Tertiary \\
\hline 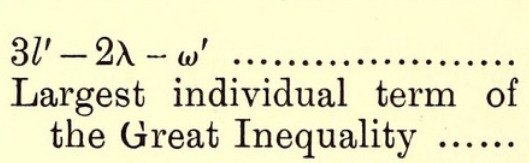 & $\begin{array}{r}\text { " } 26.79 \\
-1522 \cdot 78\end{array}$ & $\begin{array}{l}{ }^{\prime \prime} \\
+10 \cdot 10 \\
+11 \cdot 18\end{array}$ & $\begin{array}{l}{ }^{\prime \prime} \\
+0.02 \\
+0.41\end{array}$ \\
\hline
\end{tabular}

(See Les Annales, xi., p. 121, \&c.)

In the last case the next term may be estimated at about $0^{\prime \prime} \cdot 04$. For such a quantity to have any real significance we must know the mass of Saturn correctly within its $\frac{4}{30000}$ part, and the annual motion of Jupiter within $0^{\prime \prime} \cdot 00008$. Both of these requirements are beyond our power of attainment; in short, terms of the tertiary order are of very little importance, whilst those of the next order are quite negligible in the theories to which an algebraical development can be applied.

It may, however, be necessary to include such terms in the consideration of the secular perturbations, but in this case it is possible to give general expressions of great simplicity, extending to any powers of the eccentricities and mutual inclinations, and these will be found in the last table of the present paper.

Chessin has shown (Ast. Journal, No. 442, 1898) that it is possible to simplify the expressions for the computation of the values of the Newcomb operators; he gives the following example :-

Newcomb-

$$
\begin{aligned}
7680 \Pi_{4}^{6}= & \mathrm{D}^{6}+(8 i-25) \mathrm{D}^{5}+\left(20 i^{2}-130 i+185\right) \mathrm{D}^{4}+\left(-80 i^{2}+340 i-255\right) \mathrm{D}^{3} \\
& +\left(-80 i^{4}+640 i^{3}-1765 i^{2}+2280 i-1466\right) \mathrm{D}^{2} \\
& +\left(-128 i^{5}+1360 i^{4}-5280 i 3+9535 i^{2}-8454 i+3096\right) \mathrm{D} \\
& +\left(-64 i^{6}+800 i^{5}-3740 i^{4}+8200 i 3-8588 i^{2}+3608 i\right) .
\end{aligned}
$$


Chessin-

$\Pi_{4}^{6}=6 \Pi_{6}^{6}+2(i-5) \Pi_{5}^{5}-\left(\frac{3}{4} i-2\right) \Pi_{4}^{4}-\left(i-\frac{1}{4}\right) \Pi_{3}^{3}-\frac{1}{12}(2 i-1) \Pi_{2}^{2}-\frac{9}{3} \frac{9}{2}(5 i-1) \Pi_{\mathrm{r}}^{\mathrm{r}}-\frac{2}{15} i$

Chessin's formula has two advantages; firstly, it is much shorter; secondly, it throws the computation of the secondary terms on to those of the first. In ordinary course the primary terms must be computed first, and it is fitting that they should form the basis for the secondary and higher terms. But neither Newcomb nor Chessin gave a general expression for the operators, and, in point of fact, it requires a very lengthy calculation to check, far less to extend, Newcomb's tables.

Let us suppose that we are dealing with the primary operator $\Pi_{8}^{8}$; Newcomb's formula starts thus-

$$
\begin{gathered}
10321920 \Pi_{8}^{8}=256 i^{8}-8960 i 7+130592 i^{6}-1023120 i^{5}+462807 i^{4}+\& \mathrm{c} . \\
\text { plus terms in } \mathrm{D}, \mathrm{D}^{2} \ldots \text { to } \mathrm{D}^{8} .
\end{gathered}
$$

The figures bear no obvious relation to each other, and have to be taken on trust; besides this, the computation for a particular value of $i$ is exceedingly arduous. The length of the expression for $\Pi_{9}^{9}, \Pi_{\mathrm{ro}}^{\mathrm{ro}}$, \&c., is appalling; it is true that the use of the Chessin formulæ would shorten the calculation, but Chessin does not give the constants his method requires for operators beyond $\Pi_{6}^{6}$ and $\Pi_{0}^{4}$. Chessin's constants for $\Pi_{n}^{n}$ are, however, not difficult to find, as they are connected with certain Besselian series for $e$ used in Hansen's planetary theory.

Newcomb gives, on p. 13 of vol. v. of the Astronom. Papers of the American Ephemeris, the general recurrent formula by which he builds up $\Pi_{n}^{n}$; it is-

$$
\begin{aligned}
& 2(n+1) \Pi_{n+\mathrm{r}}^{n+\mathrm{r}}=\left(k_{\mathrm{r}}^{\prime} \mu+h_{\mathrm{r}}^{\prime} \mathrm{D}\right) \Pi_{n}^{n} \\
& +\left(k_{2}^{\prime \prime} \mu+h_{2}^{\prime \prime} \mathrm{D}\right) \Pi_{n-1}^{n-1} \\
& \text { +.................. } \\
& +\left(k_{n+1}^{n+1} \mu+h_{n+1}^{n+1} \mathrm{D}\right) \Pi_{\circ}^{\circ}
\end{aligned}
$$

in which the factors $k$ and $h$ depend upon the developments of the equation of the centre and the logarithm of the radius vector in terms of the mean anomaly. The succession of the values of the $k$ 's given by Newcomb (p. 22 loc. cit.) are-

$$
2, \frac{5}{2}, \frac{13}{4}, \frac{103}{24}, \frac{1097}{192}, \frac{1223}{160}, \frac{47273}{4608}, \frac{556403}{40320}
$$

What the next fraction will be is by no means clear, but it will be seen immediately that the values are really not wanted, as a transformation at once discloses the values of the successive terms. Let us write out the Newcomb values for $\Pi_{1}^{1}, \Pi_{2}^{2}$ in the following form :- 


\begin{tabular}{|c|c|c|c|}
\hline$\Pi_{0}^{\circ}$ & $2 \Pi_{1}^{I}$ & $8 \Pi_{2}^{2}$ & $48 \Pi_{3}^{3}$. \\
\hline $\begin{array}{c}-(2 i+\mathrm{D}) \\
-(5 i+3 \mathrm{D}) \\
-(26+17 \mathrm{D}) \\
\& \mathrm{c} .\end{array}$ & $\begin{array}{l}-1 \\
-(2 i+\mathrm{D}) \\
-(10 i+6 \mathrm{D}) \\
\quad \& \mathrm{c} .\end{array}$ & $\begin{array}{l}-1 \\
-(2 i+\mathrm{D})\end{array}$ & -1 \\
\hline
\end{tabular}

which is read as follows:-

$$
0=-(2 i+\mathrm{D}) \Pi_{\mathrm{o}}^{\circ}-2 \Pi_{\mathrm{r}}^{\mathrm{r}} \& \mathrm{c} .
$$

Subtract now $3(a)$ from $(b)$, and generally subtract whole multiples of (a) (b)... from the following letter and the following table results :-

\begin{tabular}{|c|c|c|c|}
\hline$\Pi_{\mathrm{o}}^{\circ}$ & $2 \Pi_{1}^{\mathrm{r}}$ & $8 \Pi_{2}^{2}$ & $48 \Pi_{3}^{3}$. \\
\hline $\begin{array}{c}-(2 i+\mathrm{D}) \\
i \\
2 i \\
\& \mathrm{c} .\end{array}$ & $\begin{array}{l}-1 \\
-2 i+3-\mathrm{D} \\
2 i-1 \\
\quad \& \mathrm{c} .\end{array}$ & $\begin{array}{l}-1 \\
-2 i+6-\mathrm{D}\end{array}$ & -1 \\
\hline
\end{tabular}

The final results are presented in Table I.A, which contains precepts for its indefinite extension. The $\Pi_{0 . n^{\prime}}^{o . n^{\prime}}$ will be found in Table I.B. It will also. be seen that the property-

$$
\Pi_{j, j^{\prime}}^{n, n^{\prime}}=\Pi_{j}^{n} \times \Pi_{\circ . j^{\prime}}^{o . n^{\prime}}
$$

falls naturally into the scheme of these tables.

In practice we first compute-

and-

$$
2 \Pi_{1}^{1}, 8 \Pi_{2}^{2}, 48 \Pi_{3}^{3} \ldots \& \mathrm{c} .
$$

then-

$$
\begin{aligned}
& 2 \Pi_{0.1}^{0.1}, 8 \Pi_{0.2}^{0.2}, 48 \Pi_{0.3}^{0.3} \ldots \& c . \\
& 4 \Pi_{\Gamma, 1}^{1.1}, 16 \Pi_{2.1}^{2.1}, 96 \Pi_{3.1}^{3.1} \ldots \& c .
\end{aligned}
$$

and so on, step by step, each individual step being simple enough, and natural checks on the results abound. This method requires, however, the quantities $\mathrm{D}^{q} \Pi_{\circ}^{\circ}$ where $q-1$ is equal to the highest power of $e$ or $e_{\mathrm{r}}$, which has to be included. Thus in actual work we must compute-

$2 \Pi_{1}^{1}, 8 \Pi_{2}^{2}, 48 \Pi_{3}^{3} \ldots \& \mathrm{c}$.

$\mathrm{D} 2 \Pi_{1}^{\mathrm{I}}, \mathrm{D} 8 \Pi_{2}^{2}, \mathrm{D} 48 \Pi_{3}^{3} \ldots \& \mathrm{c}$.

$\mathrm{D}^{2} 2 \Pi_{1}^{1}, \mathrm{D}^{2} 8 \Pi_{2}^{2}, \& \mathrm{c} . \ldots \& \mathrm{c}$. 
The presence of the $\mathrm{D}$ operator in no way alters the tables, thus-

And so on.

$$
\begin{aligned}
& 0=(-2 i-\mathrm{D}) \Pi_{\mathrm{o}}^{\circ}-2 \Pi_{\mathrm{r}}^{\mathrm{r}} . \\
& 0=\mathrm{D}^{q}(-2 i-\mathrm{D}) \Pi_{\mathrm{o}}^{\circ}-\mathrm{D}^{q} 2 \Pi_{1}^{\mathrm{1}} .
\end{aligned}
$$

As pointed out in the tables, the forms for $\Pi_{-n \cdot n^{\prime}}^{n \cdot n^{\prime}}$ or $\Pi_{n \cdot-n^{\prime}}^{n \cdot n^{\prime}}$ are included. It must be remembered that such an operator as $\Pi_{-1}^{1}$ cannot act alone ; in actual work it will be joined to another of at least the same order but with a positive suffice, the final form being $\Pi_{-I, I}^{\mathrm{r} . \mathrm{I}}$ or $\Pi_{-I .2}^{\mathrm{I} .2}$, and so on. In fact, although of primary form, such are closely connected with the secondary terms. As the secondary, tertiary, and higher terms are seldom required, it is, as already mentioned, advisable to make them dependent on the first order terms. In the tertiary terms we first meet with the quantity $i^{2}$, but it can be eliminated by the introduction of an $i \mathrm{D}$ operator which will make the numerical work simpler.

The tables for the secondary terms (Tables II.A and II.B and III.A and III.B) require no further explanation-the examples attached to each show their use.

The paper concludes with a symbolic expression for the non-periodic or secular part of the perturbative function, which by simple multiplications will give the expansion to any powers of the excentricities and mutual inclination. Examples are added, which can be compared with the known results given by Newcomb and other investigators.

The happy introduction by Newcomb of the two operators-one of which is purely symbolical-D and $\Pi$, has vastly simplified the development of the perturbative function. The curious properties of the D operator have been dealt with in the Monthly Notices of the Royal Astronomical Society for June and December, 1909.

\section{JoHANNESBURG,}

September 5, 1911. 


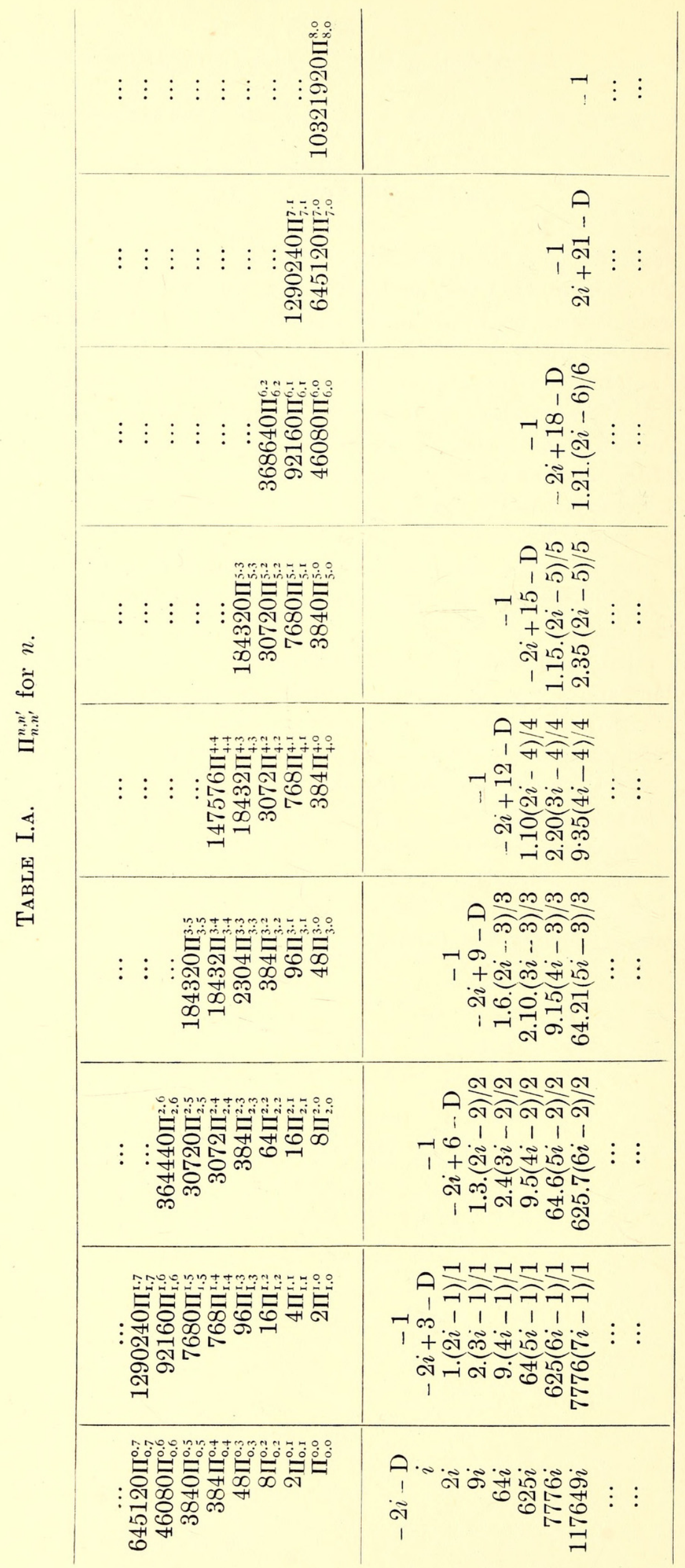


Algebraical Development of the Elliptic Perturbative Function. 309

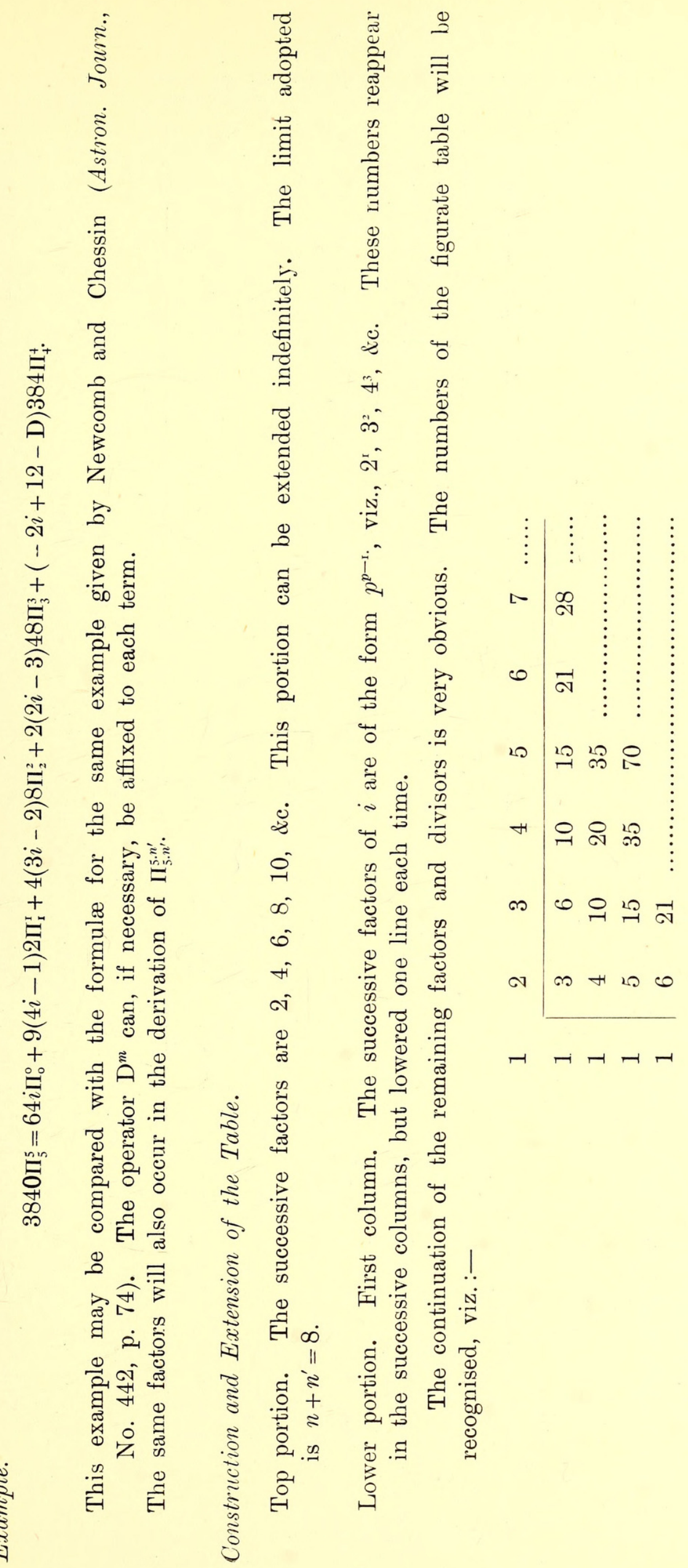




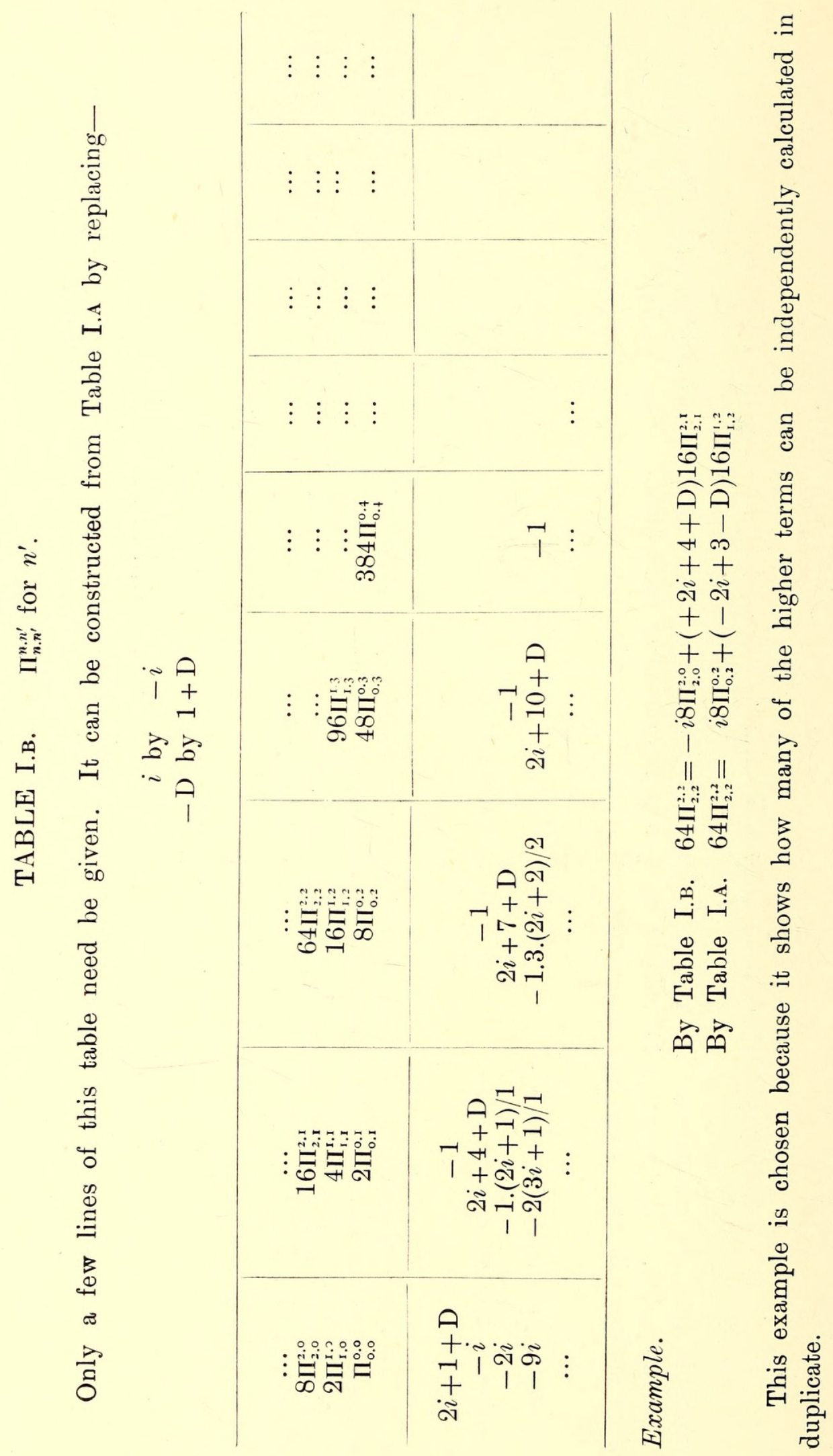


Algebraical Development of the Elliptic Perturbative Finction. 311

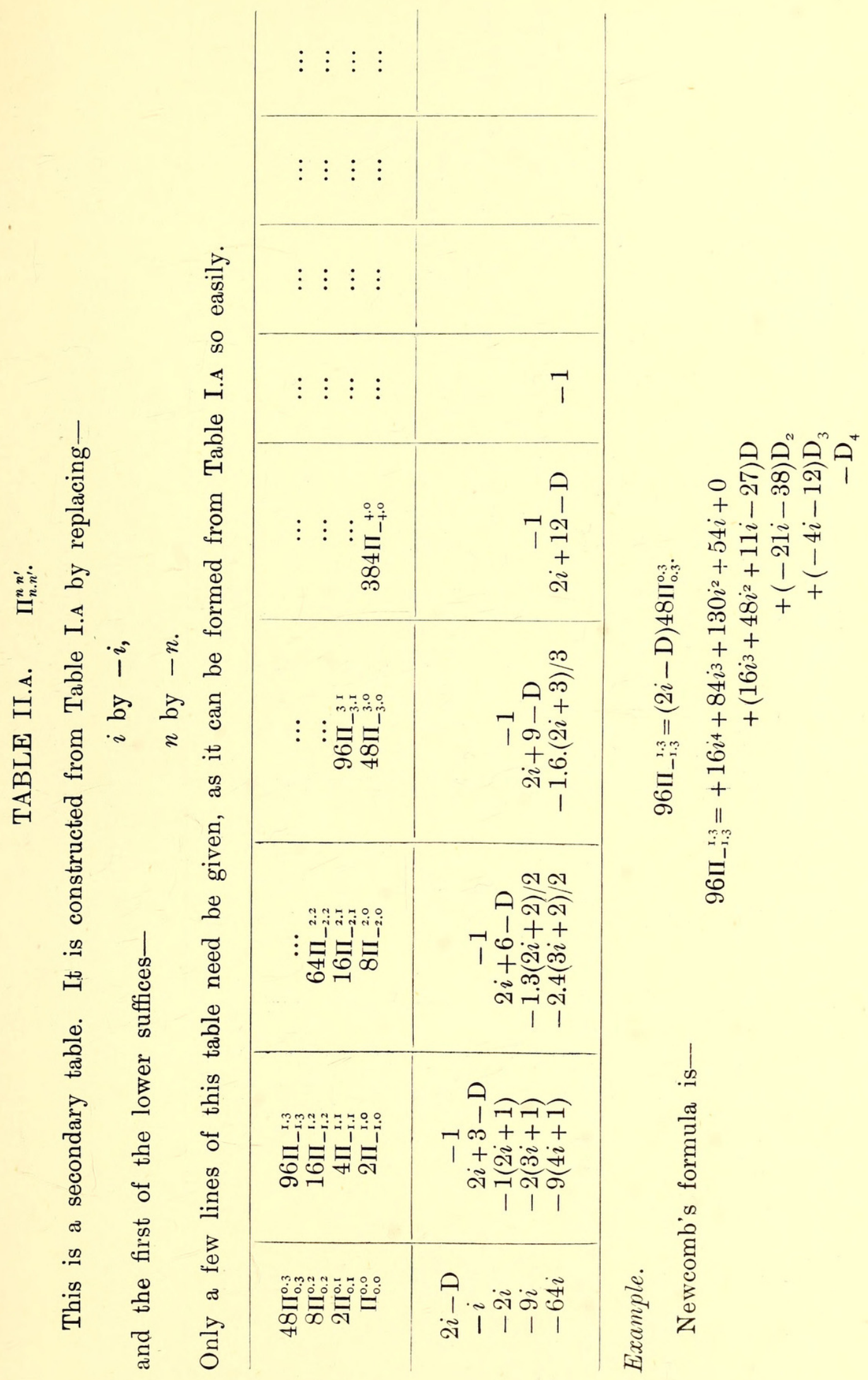




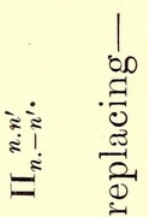

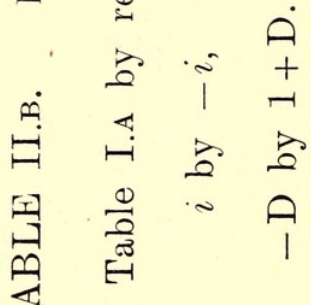<smiles>C1CCCC1</smiles>

离

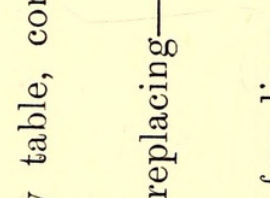

त्ञ

苞

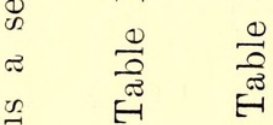

Eี

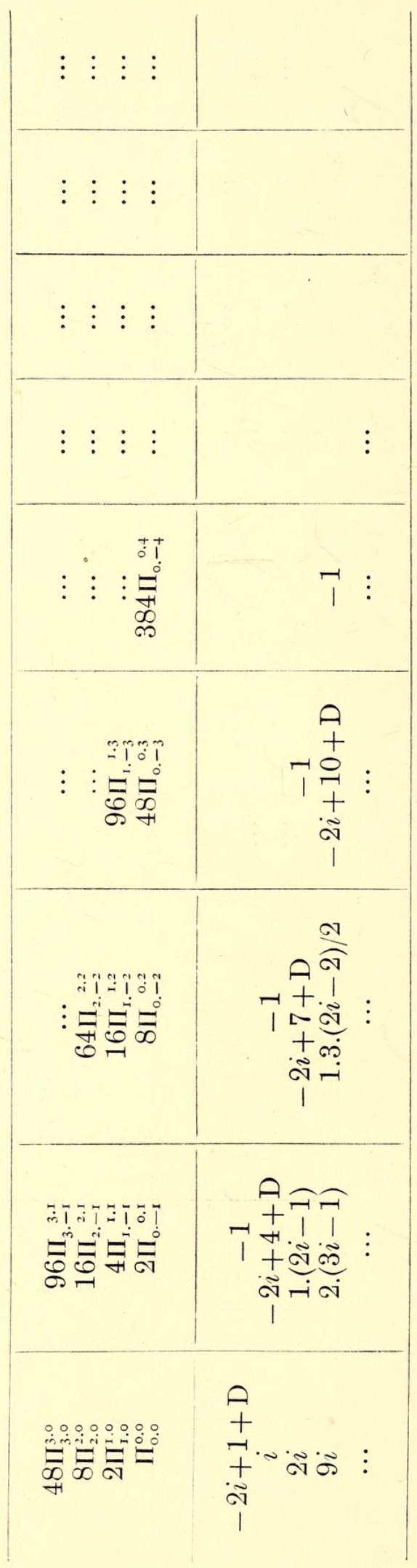

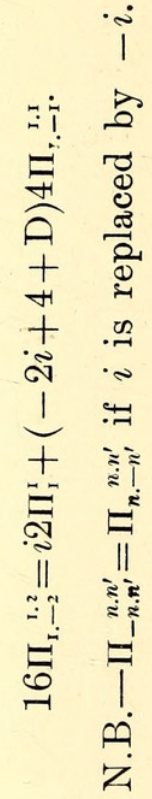

芯 


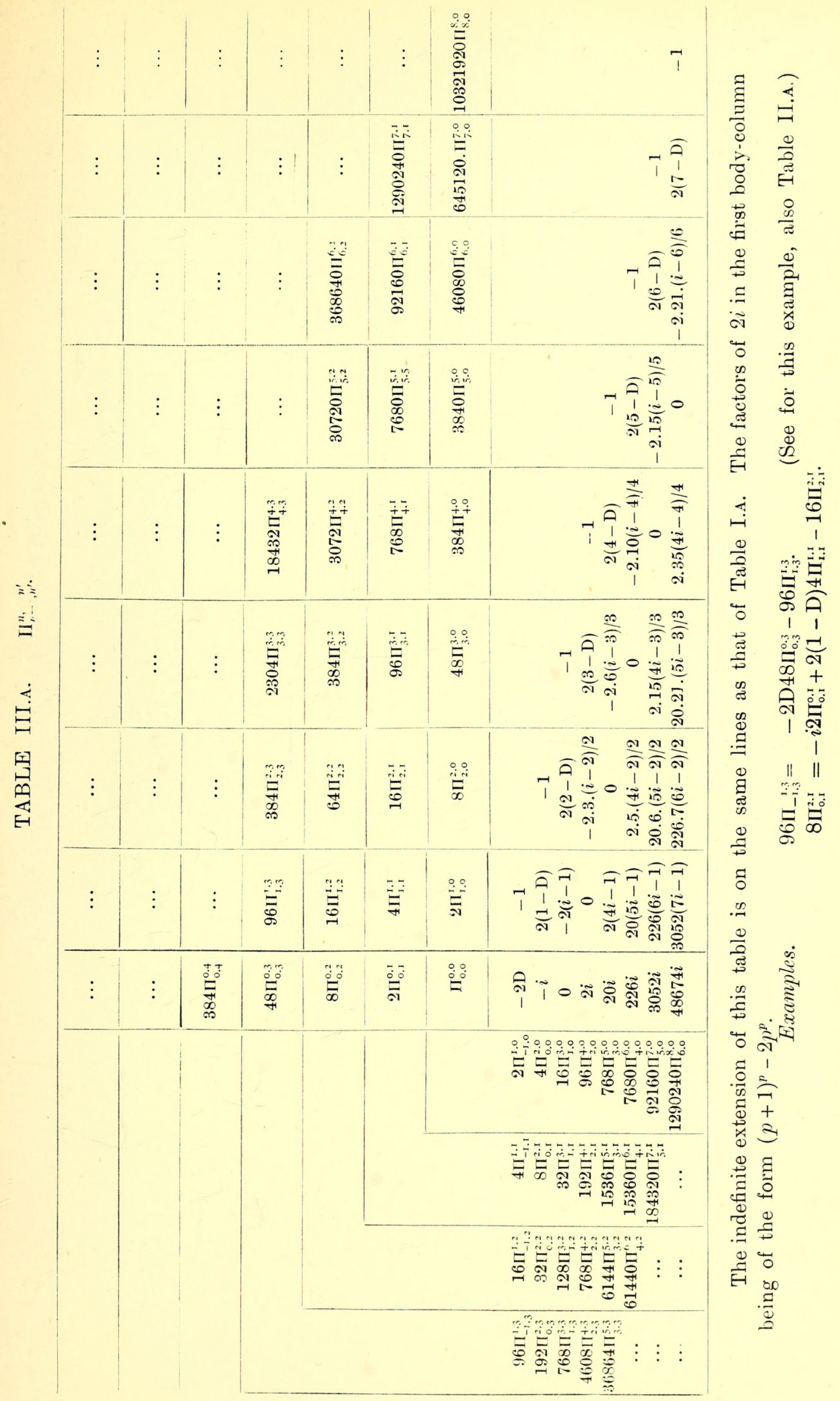


ind

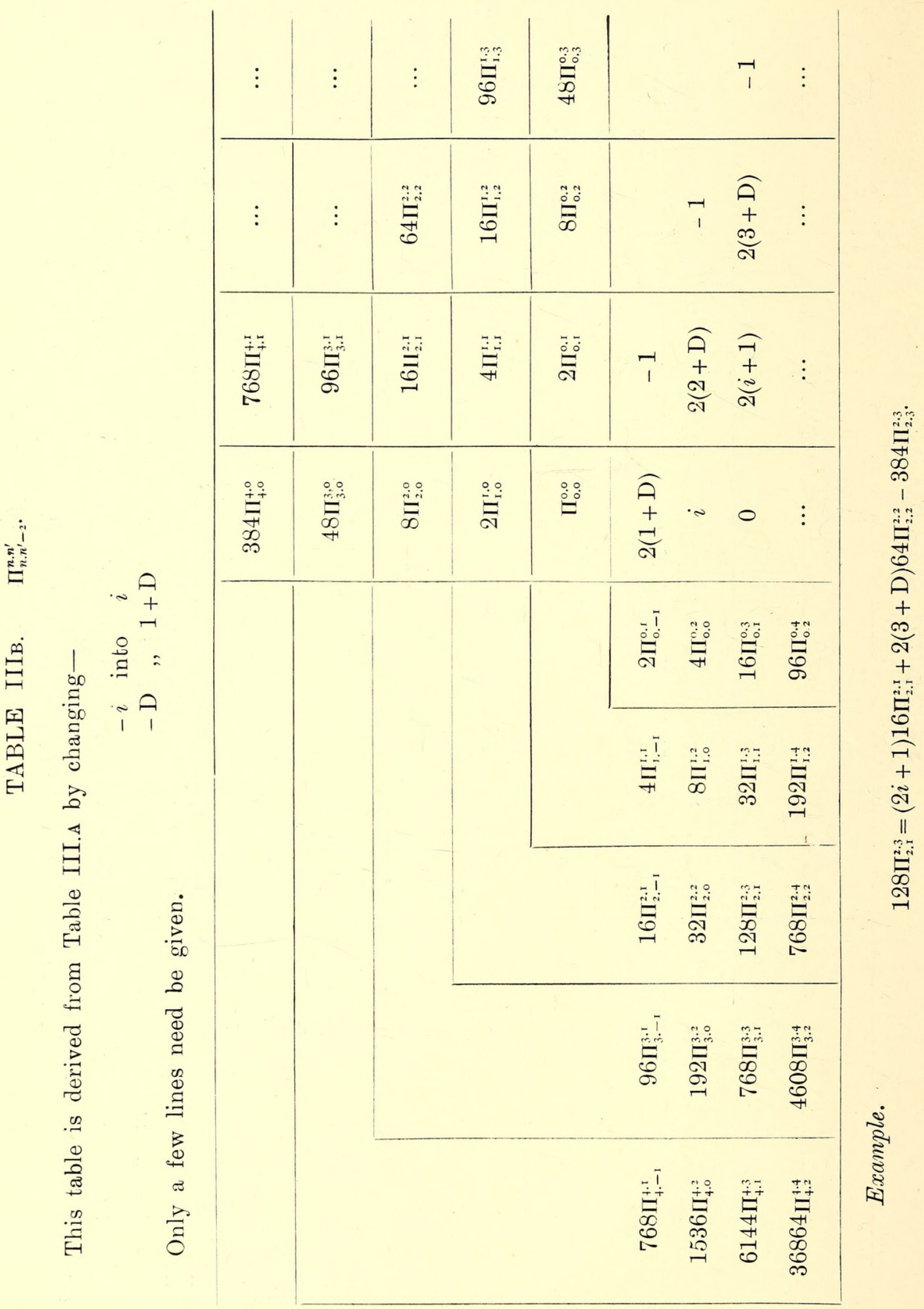


Algebraical Development of the Elliptic Perturbative Function. 315

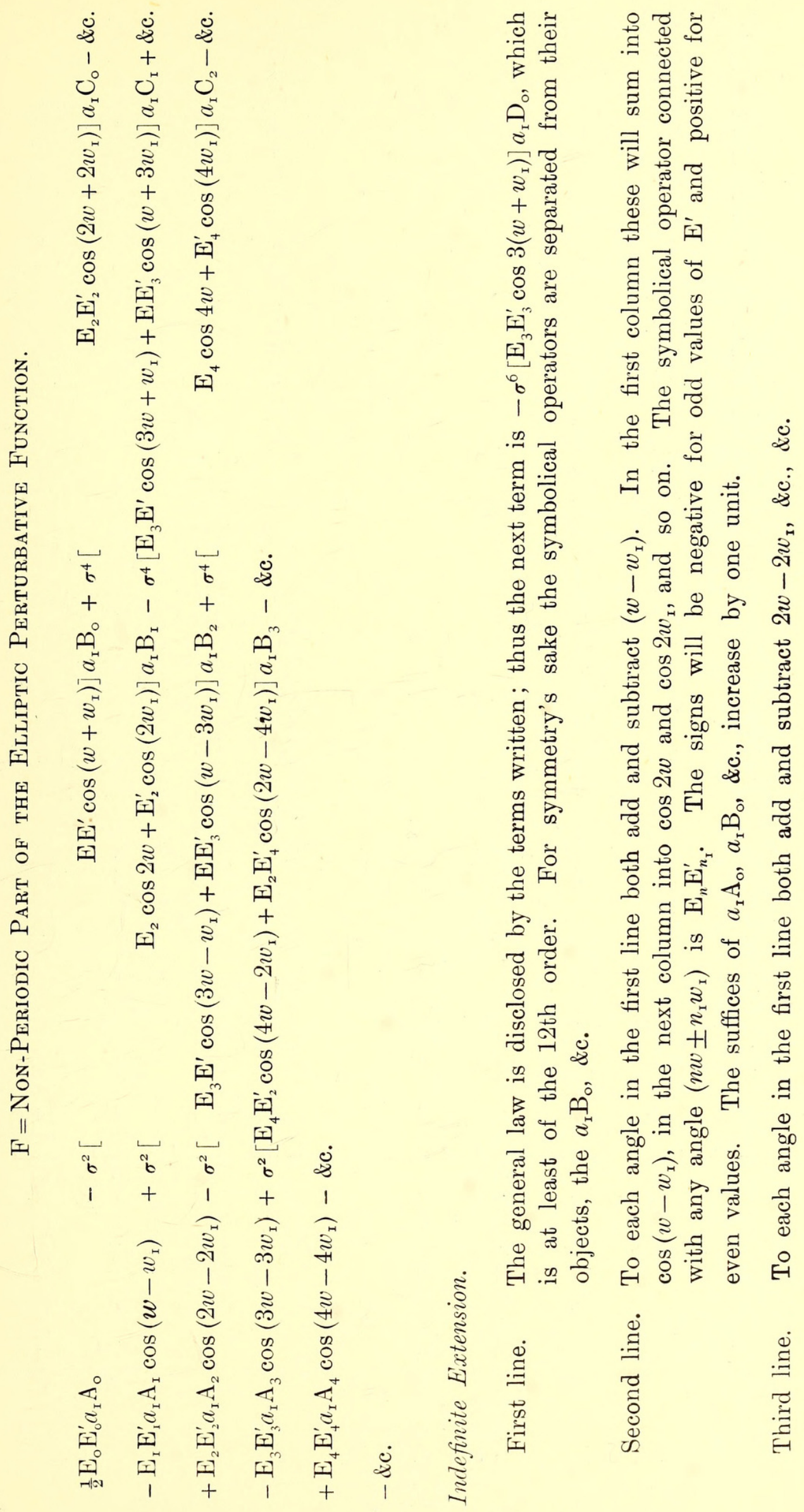




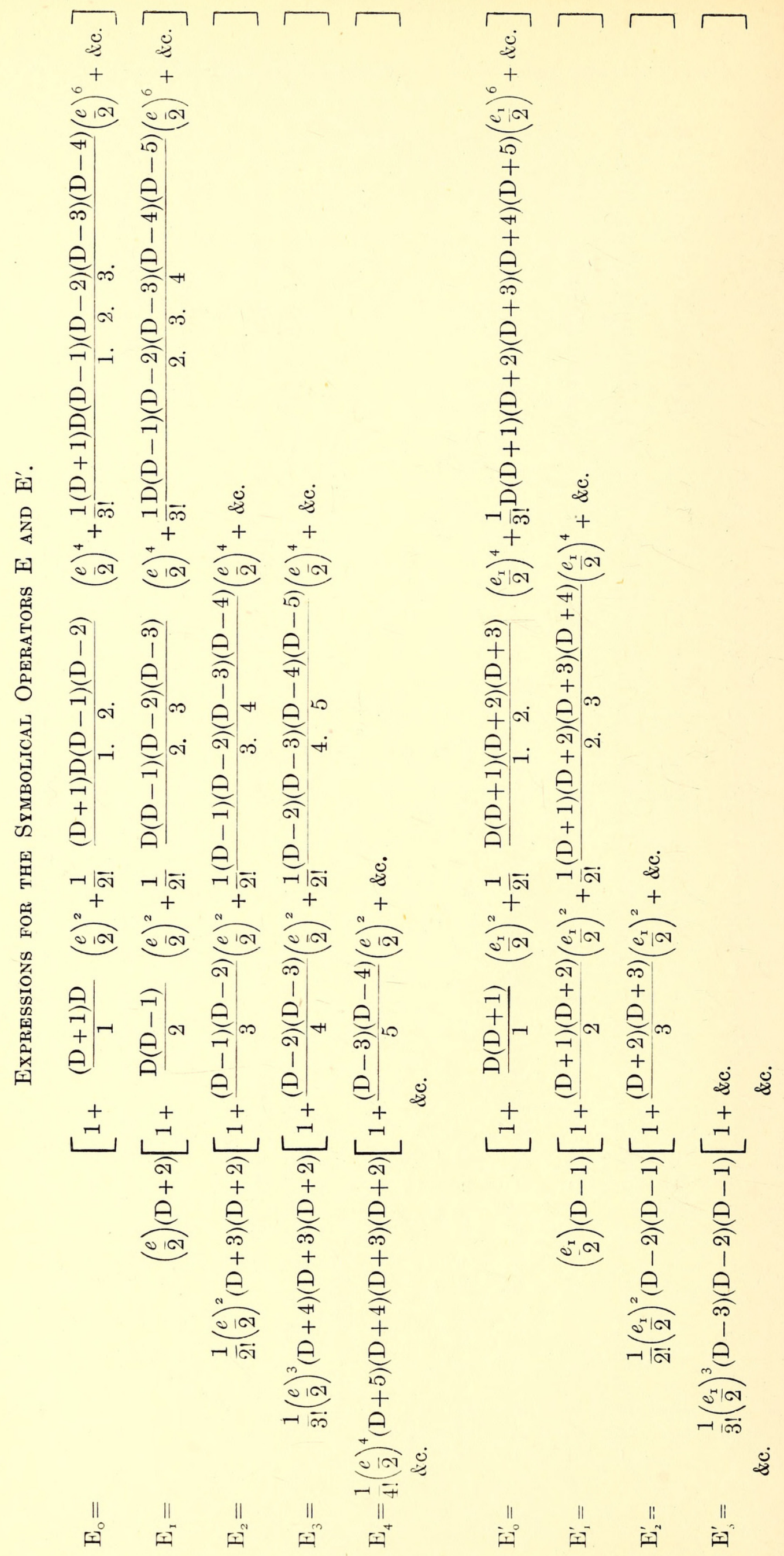


Algebraical Development of the Elliptic Perturbative Function. 317

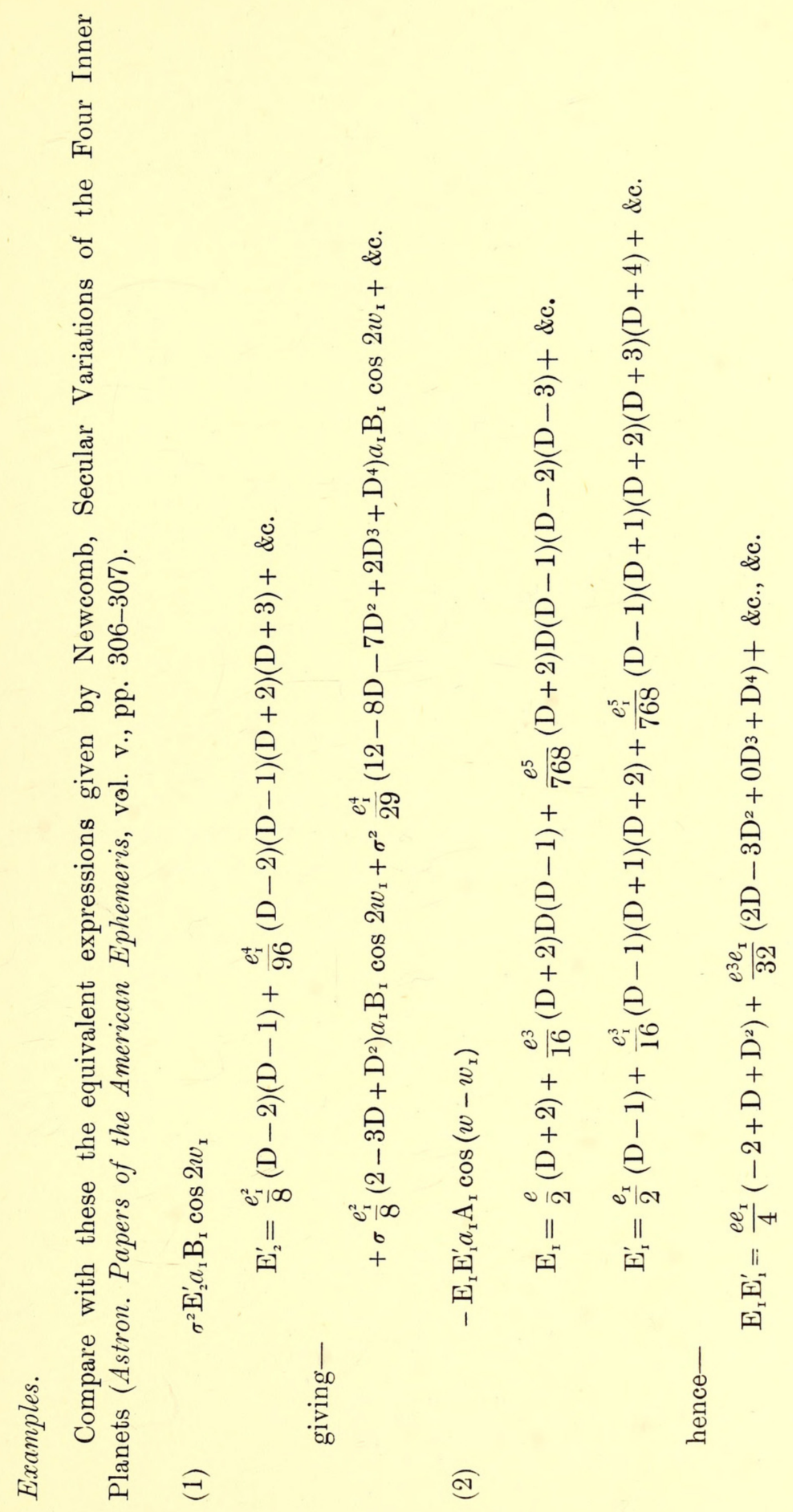




\section{$2 \mathrm{BHL}$ Biodiversity Heritage Library}

Innes, R T A . 1910. "THE ALGEBRAICAL DEVELOPMENT OF THE ELLIPTIC PERTURBATIVE FUNCTION USED IN THE THEORIES OF PLANETARY MOTION." Transactions of the Royal Society of South Africa 2, 301-317. https://doi.org/10.1080/00359191009519390.

View This Item Online: https://www.biodiversitylibrary.org/item/181596

DOI: https://doi.org/10.1080/00359191009519390

Permalink: https://www.biodiversitylibrary.org/partpdf/175496

\section{Holding Institution}

Smithsonian Libraries

\section{Sponsored by}

Biodiversity Heritage Library

\section{Copyright \& Reuse}

Copyright Status: Not in copyright. The BHL knows of no copyright restrictions on this item.

This document was created from content at the Biodiversity Heritage Library, the world's largest open access digital library for biodiversity literature and archives. Visit BHL at https://www.biodiversitylibrary.org. 